\title{
LA ADHESIÓN A LA TRADICIÓN COMO MANIFESTACIÓN DEL ARRAIGO EN LA POESÍA DE JOSÉ ANTONIO MUÑOZ ROJAS
}

\author{
BASANT MOHAMED GHETH \\ Universidad de Málaga/Universidad de Al Azhar-Egipto
}

\section{LA CONSERVACIÓN DE LA TRADICIÓN: UNA FORMA DEL ARRAIGO}

José Antonio Muñoz Rojas (1909-2009) nació en Antequera, enclave que ocupa una posición singular tanto en la geografía como en la historia. Aunque se trata de una ciudad que se ha visto sometida a lo largo del tiempo a varias invasiones y superposiciones humanas, la fidelidad de la población antequerana hacia su tierra y su tradición es sorprendente. Y nuestro poeta está especialmente vinculado tanto con la historia y el pasado de su ciudad natal como con la tradición literaria española. Se trata de un autor erudito ${ }^{1}$ cuya labor literaria abarca casi siete decenios (1929-2004), aunque la crítica mantuvo un largo silencio ante su producción. Dámaso Alonso, exponiendo los conceptos del arraigo y

${ }^{1}$ A este respecto, los artículos de José Antonio Muñoz Rojas reunidos en Antequera, norte de mi pluma (pról. de F. López Estrada, Unicaja, Málaga 1998) demuestran un gran conocimiento de la historia de su ciudad y de su gente, pasando en esta obra por la historia de las distintas iglesias de Antequera desde la primera San Salvador, hoy desaparecida, hasta las del siglo XVIII (págs. 33-34). Además, presenta al lector muchos personajes históricos relacionados con esta ciudad como José María Fernández (págs. 35-41 y págs. 59-64), Ignacio de Toledo (págs. 53-58), Ramón Sorzano (págs. 43-44) y otros más. En el mismo contexto destacamos que el poeta, a lo largo de esta obra, hace mención de varios familiares escritores, a los cuales conoció o por su abuela Teresa o a través de las bibliografías o por toparse con un documento de primera mano sobre ellos. 
desarraigo durante los años cuarenta, nos presenta a Muñoz Rojas como uno de los prototipos de la tendencia arraigada: «vinculado y centrado en el mundo a través de la tierra nativa: Málaga, y sobre todo la región de Antequera ${ }^{2}$, y aquí lo presentamos como un poeta arraigado en la tradición literaria a través de dos obras que pertenecen al mismo período tratado por el gran filólogo.

La tradición es uno de los vínculos culturales que ligan al hombre con su espacio. Por ello no sería pertinente separar un lugar de su historia y su tradición $y$, en este sentido, Niall Binns, partiendo de una perspectiva ecológica, defiende la noción del bosque en la identidad latinoamericana como lugar del arraigo, relacionando este espacio con su tradición. Para él, el bosque es sinónimo de «un depositario de valores autónomos, de los mitos y relatos fundacionales del lugar que la potencia colonizadora necesita anular para mejor dominar» ${ }^{3}$.

Es curioso que algunos de los poetas exiliados durante la guerra civil encontraran en la vuelta a la tradición, representada en su caso en la poesía popular (con sus diferentes formas: el romancero, coplas y las canciones, etc.), un motivo para arraigarse. Esta actitud se observa en Alberti que sufrió la amargura de la guerra:

La poesía - memoria que recupera el espacio y el tiempo perdidosfacilita que poetas como Alberti se replanteen una vuelta a la canción popular y al texto testimonio [...]. En realidad, a pesar de la ruptura histórica, estos poetas se esfuerzan por mantener y por continuar, si no en lo que se refiere al espacio sí en lo que afecta a la vivencia, con unos compromisos ético-estéticos ${ }^{4}$.

Por ello, podemos referirnos a la adhesión a la tradición como un tipo de arraigo. Explicándolo de otra manera: la ruptura con la tradición muestra un estado de desarraigo. Así pues, Dámaso Alonso juzga a las vanguardias — que se apartaron de su historia, abriendo sus ojos a lo nuevo y dando la espalda a lo nacional- como literaturas hechas fuera de sus tierras 5 . A pesar de ello, la adhesión al acervo cultural no supone la paralización intelectual, pues el propio sentido de la tradición no se opone a la renovación como vamos a exponer.

${ }^{2}$ D. Alonso, Poetas españoles contemporáneos, Gredos, Madrid, 1969, pág. 346.

${ }^{3}$ N. Binns, ¿Callejón sin salida?, la crisis ecológica en la poesía hispanoamericana, Prensas Universidad, Zaragoza, 2004, pág. 10.

${ }^{4}$ F. Rubio y J. L. Falcó (selección, estudio y notas), Poesía española contemporánea (1939-1980), Alhambra, Madrid, ${ }^{2} 1982$, pág. 19.

5 D. Alonso, Poetas españoles contemporáneos, págs. 163-164. Muñoz Molina tiene otra perspectiva al referirse a los movimientos vanguardistas, pues en su discurso de ingreso en la Real Academia Española en 1996 pone de relieve que la necesidad expresiva de dar cuenta del tiempo que el hombre vive hace que se buscara renovar la tradición, defendiendo que tradición y vanguardia no son posiciones adversas. Por eso, menciona el caso del vanguardismo de Max Aub que no implica acabar con la tradición: «una de las lecciones que pueden aprenderse de su obra es su doble búsqueda de lo mejor del pasado y de lo más valioso y más útil del presente» (A. Muñoz Molina, Destierro y destiempo: Dos discursos de ingreso en la Academia, Pretextos, Valencia, 2004, pág. 68). 


\section{MUÑOZ ROJAS, UN ESCRITOR ARRAIGADO EN LA TRADICIÓN ${ }^{6}$}

Lo que nos concierne en este trabajo es la tradición literaria, sobre todo la poesía. Hay dos tipos de poesía relacionados, y al mismo tiempo distintos, que mencionamos aquí como ejemplo de la persistencia y traspaso de la tradición en el autor: la poesía popular7 y la tradicional ${ }^{8}$. Según la exposición de Ramón Menéndez Pidal, el receptor en el caso de la poesía popular es pasivo, o bien, un fiel transmisor de lo que oye o recibe, y, por eso, la traspasa como es, sin cambios, llevándola de una generación a otra. En la poesía tradicional el lector o receptor contribuye con su imaginación y emoción en la creación de la obra heredada. Este carácter evolutivo de la poesía tradicional es el que plantea Marcos Arévalo consolidando la idea de la tradición como manifestación de la continuidad cultural de un pueblo.

Nuestro poeta se refiere a la idea de continuidad y originalidad de la obra literaria: «un poeta no es más que una voz personal y continuada, articulada en su propio vivir y sentir, de tantas voces como le resuenan dentro y a las que

${ }^{6}$ El concepto de «tradición» es amplio y ambiguo a la vez. La palabra se deriva del latín traditio que significa «entrega de una cosa». Con este término se refiere a la «Circunstancia de tener una cosa su origen o raíces en tiempos pasados y haber sido transmitida de unas generaciones a otras» (M. Moliner, Diccionario de uso del Español, Gredos, Madrid, 1990, pág. 1354). Javier Marcos Arévalo señala que la tradición actualiza y renueva el pasado desde el presente, de ahí su papel en la conservación de la continuidad cultural. En este proceso de desarrollo se crean nuevas formas de expresión cultural (J. Marcos Arévalo, «La tradición, el patrimonio y la identidad», Revista de Estudios Extremeños, 60, 3, 2004, págs. 925-956). Es de señalar que cuando empleamos la palabra «tradición» no nos referimos a los poetas clásicos precisamente, ellos mismos tienen una tradición y no la ignoran. Quintiliano (35 d. C.-100 d. C.), por ejemplo, se sirve de la tradición anterior y apunta en uno de sus libros que la mayoría de su contenido no es de su cosecha sino extraído de otros autores (J. Fernández López, Quintiliano y la retórica, Amigos de la Historia de Calahorra, Murcia, 1996, pág. 15). De aquí la ambigüedad de la «tradición» respecto al tiempo.

${ }^{7}$ Menéndez Pidal plantea el concepto de poesía popular defendiendo: «Toda obra que tiene méritos especiales para agradar a todos en general, para ser repetida mucho y perdurar en el gusto público bastante tiempo, es obra popular [...]. El pueblo escucha o repite estas poesías sin alterarlas o rehacerlas; tiene conciencia de que son obra ajena, y como ajena hay que respetarla al repetirla» (R. Menéndez Pidal, «Poesía popular y poesía tradicional», en Obras completas de Ramón Menéndez Pidal, XI: Estudios sobre el romancero, II, Espasa-Calpe, Madrid, 1973, pág. 444.

${ }^{8}$ El gran erudito explica también qué es la poesía tradicional, ofreciéndonos un aspecto muy interesante que la distingue de la popular: «Pero existe otra clase de poesía más encarnada en la tradición, más arraigada en la memoria de todos, de recuerdo más extendido y más reiterado; el pueblo lo ha recibido como suya, la toma como propia de su tesoro intelectual, y al repetirla, no lo hace fielmente de un modo casi pasivo como en los casos precitados, sino que sintiéndola suya, hallándola incorporada en su propia imaginación, la produce emotiva e imaginativamente y por tanto la rehace en más o en menos considerándose él como una parte del autor [...]. La esencia de lo tradicional está, pues, más allá de la mera recepción o aceptación de una poesía por el pueblo...; está en la reelaboración de la poesía por medio de las variantes» (págs. 444-445). 
da vida con la suya propia»`9. Este ideal que tenía Muñoz Rojas coincide con el de su admirado T. S. Eliot, visión que implica una conciencia del pasado y del presente. Por eso, Andrés Trapiello destaca como característica de la obra del antequerano la «lealtad al pasado y la tradición; lealtad al presente y afirmación del futuro» ${ }^{10}$. Las cosas del campo reúne con su originalidad y clasicismo estos rasgos: «Todas ellas son cosas con alma, es decir, a su manera, fieles también a su fe, leales a su historia y su pasado, consecuentes con su poesía» ${ }^{11}$.

Es de añadir que Aquilino Duque Gimeno, en un artículo publicado con motivo del homenaje a Muñoz Rojas, planteó el tema explicando que nuestro poeta tenía conciencia desde su estancia en Inglaterra de que hay dos nociones contradictorias: la primera es la historia como continuidad y tradición; y la segunda es la historia como ruptura incesante. En Inglaterra precisamente se había dicho que la educación de un niño da comienzo cien años antes de su nacimiento. Es decir, se adaptaba el primer concepto de la historia. De sobra sabía Muñoz Rojas que la suya databa de varias generaciones. El crítico, tal como Dámaso Alonso en su referencia a lo clásico en Las cosas del campo, habla de esta obra maestra de nuestro autor para resaltar el triunfo de la tradición sobre la revolución que, en palabras de Aquilino Duque, «hizo posible que en España se mantuviera una nobleza de la tierra, una aristocracia del campo capaz de labrar una herriza y guardar con amor un libro viejo» ${ }^{12}$.

Casi todos los estudiosos de la obra del antequerano coinciden en la existencia de muchos elementos tradicionales en su obra, tanto a nivel temático como a estilístico. Cuando empleamos aquí la calificación «clásico», nos referimos a uno de dos significados: o a un modelo digno de imitación, o a lo relativo a la literatura o al arte de la Antigüedad griega y romana. En realidad, la obra de Muñoz Rojas no solo ofrece un conocimiento e influencias de la tradición clásica, sino también ella en sí misma se describe como tal. Es un tópico ya que nuestro poeta antequerano es un clásico moderno ${ }^{13}$. Dámaso Alonso explica en su carta a Muñoz Rojas, tan citada por la crítica y publicada después en sus

9 J. A. Muñoz Rojas, «La poesía de Fernando Ortiz», El Correo de Andalucía, Suplemento cultural (La mirada), 20 de mayo, 1994, pág. 33.

10 A. Trapiello, «Pórtico para José Antonio Muñoz Rojas», El Correo de Andalucía, Suplemento cultural (La mirada), 85, 31 de mayo, 1996, pág. 31.

${ }^{11}$ A. Trapiello, loc. cit.

12 A. Duque Gimeno, «Las rosas como son», Boletín de la Real Academia Sevillana de Buenas Letras: Minervae Baeticae, 38, 2010, pág. 229. También disponible en www.institucional.us.es/revistas/rasbl/38/art 20.pdf [consulta: 15 de diciembre de 2014].

${ }^{13}$ Dámaso Alonso lo describe como «clásico moderno» en «Carta a J. A. Muñoz Rojas: Sobre la mayoría y la minoría», Obras completas, Gredos, Madrid, IV, 3. parte, pág. 303. También, Álvaro García lo describe como «un poeta tan clásico y tan nuevo» (Á. García, «Muñoz Rojas, el poeta joven», Sur, 13 de abril, 1997, pág. 25). Ana Gómez Torres reincide en la calificación como «un clásico moderno» (A. Gómez Torres, «José Antonio Muñoz Rojas, un clásico moderno, en edición de C. Cuevas», Sur suplemento «cultural» en el monográfico Homenaje a Dámaso Alonso, 27 de enero, 1990, pág. II). Se editó además un monográfico titulado «José Antonio Muñoz Rojas: clásico y moderno» en Quimera (2006). 
Obras completas, las razones por las cuales está considerado como clásico moderno, un apodo que lo va acompañando después. El eminente filólogo escribe sobre Las cosas del campo — donde Enrique Baena ve la unión de las formas tradicionales cultas y populares-:

[...] yo te debo decir que hay en ella una diafanidad, una serenidad, una ponderada vitalidad, que la hacen verdaderamente clásica. Por lo menos lo que yo creo que debe ser un clásico moderno: vitalidad serena; por vital de hoy; por serena, de siempre ${ }^{14}$.

Ahora bien, la diafanidad, la serenidad y, sobre todo, la vitalidad le dan un carácter clásico, digno de ser imitado. Por su parte, Julio Neira encuentra en tres obras de Muñoz Rojas las razones suficientes para decir que es un poeta clásico, cuya obra es inmortal y un modelo para seguir ${ }^{15}$.

Además, Juan Luis Hernández Mirón apunta que la inmersión de nuestro poeta en la tradición literaria no significa de ninguna manera una imitación ciega del estilo o de los motivos de esa literatura, pues la originalidad del poeta y su personalidad propia palpitan siempre en su producción dándole un especial carácter:

El acervo de motivos literarios que le ha proporcionado la tradición se reviste de una originalidad y estilo propios y personalísimos; si las actitudes vitales del poeta están caracterizadas por la contención o por el intimismo que predominan en la estética clásica y renacentista, en la Escuela Andaluza, sin embargo, no cabe hablar en él de imitación, sino de una asunción y asimilación tan arraigadas que la tradición pasa desapercibida. La voz personalísima de Muñoz Rojas opera una profunda transformación en todas sus fuentes, inaugurando, sin duda alguna, nuevos caminos en las letras hispánicas y un nuevo sentimiento del amor, de la hermosura del campo y de la Naturaleza ${ }^{16}$.

Es un poeta arraigado en la tradición literaria andaluza comparable con sus antepasados antequeranos. Fernando Lázaro Carreter afirma que el arte literario de José Antonio es el «último vástago» del lejano tronco de los poetas de Antequera desde el siglo XVII, tal como Pedro Espinosa, Carvajal y Robles,

${ }^{14}$ D. Alonso, loc. cit.

15 Sobre este carácter de su poesía Neira explica que la vigencia de Las cosas del campo para futuras generaciones por ser testimonio fiel de una vida rural ya desaparecida, que cualquier investigador apreciará en siglos futuros como descripción de las formas de vida en la sociedad española de mediados del siglo XX. Sus otras obras también se comparan con los grandes de la época, así pues Las musarañas (1957) y Las sombras (1976) son indagación profunda de la conciencia personal, al nivel del mejor Juan Ramón y de Ocnos de Luis Cernuda. Por sí mismas estas tres obras citadas deberían incluir a Muñoz Rojas en el grupo de escritores cuya lectura traspasa los límites de su tiempo y le convierten en clásico (J. Neira, «Muñoz Rojas», Cuadernos hispanoamericanos, 713, 2009, pág. 111).

16 J. L. Hernández Mirón, «José Antonio Muñoz Rojas y Pedro Espinosa: El sentimiento de la Naturaleza en Las cosas del campo», Castilla: Estudios de Literatura, 1, 2010, págs. 155-156. 
Tejada o Martín de la Plaza. Pero este vástago está acrecido por su talento propio, la supervivencia de los poetas contemporáneos y, sobre todo, por «la particularidad, tan andaluza, de que este antequerano se cela y recluye en jardines que se abren para pocos $\rangle^{17}$. Efectivamente, Muñoz Rojas mostró una gran atención a los poetas áureos, como otros miembros de la generación literaria del 36, pero conoció sobre todo la obra de los poetas de Antequera de los siglos XVI y XVII. Este hecho acerca a nuestro poeta a una tradición de gran valor literario. Francisco López Estrada incide en el inestimable estilo de ellos: «[...] saben pulir el verso con cuidados manieristas, que lo dejan sorprendente por el uso de una imagen relampagueante o el de una expresión que, sobre la base de la lengua común, se convierte en un hallazgo poético» ${ }^{18}$. Pero también es un poeta que sobrevivió a los escritores de 27 y del 36, es decir, un poeta sumergido en la literatura del siglo $\mathrm{XX}^{19}$.

Ahora bien, el reflejo de la tradición se hace de una forma explícita e implícita a la vez. Explícita cuando menciona un verso o algún pasaje de otro poeta del pasado, e implícita cuando se oye la voz de otro poeta sin ninguna mención directa de su obra ${ }^{20}$.

\subsection{Poeta arraigado en la tradición cultural de su familia}

A la familia de José Antonio Muñoz Rojas pertenecen algunos literatos que contribuyeron a la formación de la tradición e historia de Antequera. La relación entre nuestro poeta y este linaje nunca se cortó, pues el nieto se acercó a la figura de algunos de sus familiares a través de su abuela materna $\mathrm{D}^{\mathrm{a}}$. Teresa de Arrese, que le relataba la historia ilustre de sus antecedentes. Además, la casa donde se crio el poeta guardaba un inapreciable tesoro representado en cartas y libros escritos desde hace siglos por quienes le precedieron. Así pues,

${ }^{17}$ F. Lázaro Carreter, «Amigos y maestros, José Antonio Muñoz Rojas», ABC literario, 31 diciembre, 1992, pág. 7.

${ }^{18}$ F. López Estrada, «A manera de prólogo sobre quién es y qué es lo que hace el autor de este libro, un antequerano de cuerpo y alma», en op. cit., pág. 8.

19 Alfonso Canales, por ejemplo, al referirse a Sonetos de amor por un autor indiferente -un libro que ofrece muchas afinidades con la poesía de Garcilaso- destacó su modernidad y antigüedad: «[...] poco se parecía aquello a los sonetarios al uso: el autor (de indiferente, nada) entroncaba con lo mejor del pasado siglo, cuya herencia tampoco resultaba tan nefanda» (El Mundo <http://www.elmundo.es/elmundo/2009/09/29/andalucia_malaga/1254213486.html> [consulta: 08 de octubre de 2014]. Además, nuestro antequerano tenía su mundo propio creado por la peculiaridad del campo que sentía.

${ }^{20}$ De hecho, una frase de la Divina Comedia figura en un poema suyo, y algunos versos de Campoamor y Lope de Vega inauguran sus libros. En Dejado ir, aparece una parte de las Cartas de Santa Teresa (Dejado ir: Estancias y viajes, Pretextos, Valencia, 1995, pág. 193). También, de un modo implícito, se oye la voz de Antonio Machado, Cernuda, Garcilaso y otros en sus libros. Lo primero que sorprende en Cantos a Rosa es la cita de Lope de Vega y un soneto de corte garcilasista con los cuales nuestro poeta inaugura el libro. Estas referencias tienen interpretaciones más hondas. De hecho, no es la primera vez que alude o habla sobre los poetas tradicionales. En su libro Amigos y maestros (Pretextos, Valencia, 1992) el autor habló sobre Góngora (págs. 15-17) y Pedro Espinosa (págs. 19-22). 
nuestro antequerano conoció a su tía $\mathrm{D}^{\mathrm{a}}$. Beatriz a través de una «figura pequeñita que andaba siempre en las palabras de mi abuela y un traje amarillo con franjas verdes que andaban en los cajones de las cómodas del cuarto de San José» ${ }^{21}$. Otro caso es el de su tía Micaela Díez de Tejada a quien conoció a través de las bibliografías sobre Bartolomé José Gallardo²2.

Gracias a las palabras inaugurales de Sonetos de amor por un autor indiferente $^{23}$ nos acercamos a tres de sus familiares aficionados a las letras. El antequerano finge haber encontrado los versos de ese libro entre las ruinas de la vieja casa familiar, comentando que había una noticia sobre aquellos Sonetos en diversas cartas y documentos familiares, pero la destrucción completa del archivo lo impide ahora «traer a colación eruditamente las citas» e identificar al autor. Después, hace mención de algunos de sus familiares en su búsqueda del autor de los Sonetos:

Hay que desechar la atribución más inmediata, la de D. T. [Se refiere a Don Trinidad de Rojas], poeta romántico de los de perilla y serrallo, versificador afortunado de distintas leyendas antequeranas, autor de un poema filosófico en cuarteto, Ignoto, y de una inacabada Historia de Antequera, porque las diferencias de estilo son tan acusadas que no vale la pena recalcarlas ${ }^{24}$.

${ }^{21}$ J. A. Muñoz Rojas, Antequera, norte de mi pluma, pág. 66.

${ }^{22}$ Muñoz Rojas nos relata en «Extraordinario carteo entre don Antonio Rodríguez Moñino y el autor, a propósito de La Dama Duende»: «Por donde menos se piensa, por las perfecciones bibliográficas de un amigo y por sus devociones gallardistas, venía yo a dar con parientes de los que no tenía noticias. Y parientes más literarios que ninguno de las historias, como que tenían correspondencia con don Bartolomé José Gallardo. Claro que nada sabía del grado de parentesco, ni poco más que unas fechas aproximadamente coincidentes» (págs. 66-67). Ante estos interesantes descubrimientos de los parientes de nuestro poeta cuyas historias están guardadas en papel, Muñoz Rojas reflexiona: «Aquí [en papeles] estaba la historia de una familia a través de unos siglos: una película de gentes distintas todas con un mismo nombre, despuntando, moviéndose un tanto, extinguiéndose luego. Cenizas animadas. De lo que habían hecho o dicho en la vida sólo quedaban firmas inseguras, líneas vacilantes sobre papeles amarillentos, con su incitante, casi sensual, olor» (pág. 67).

23 J. A. Muñoz Rojas, Obra completa en verso, C. Martínez Mesa (estudio y edición), Pretextos, Valencia, 2008, págs. 119-120. El prólogo de Sonetos de amor por un autor indiferente respeta la estructura clásica ya establecida desde Aristóteles, donde el orador no entra directamente en materia, primero hay que ganarse la atención de los oyentes. Es de observar también que hay una estrecha relación entre los tópicos clásicos salpicados a lo largo de esta obra y los personajes citados en el prólogo. Por ejemplo sobre su tío Ramiro, Muñoz Rojas comenta que mantuvo «una dignidad clásica en su manera», aunque este familiar vivió en el siglo XIX, muy alejado de este clasicismo, pero bebía de fuentes clásicas, no exento de espíritu romántico: «[...] aunque el fuego por debajo, la domeñada pasión, se manifiesten de un modo sordo y constante» (pág. 120). El tema de estos Sonetos de Muñoz Rojas es amoroso, por eso no se limita a hablar sobre su tío Ramiro sino que hace mención de Beatriz de Vibraye que fue condesa de Suzenet y mantenía relación amorosa con él. A lo que parece, nuestro poeta ha leído las cartas que los amantes intercambiaban porque menciona en sus palabras preliminares algunos detalles curiosos sobre los dos (págs. 119-120).

${ }^{24}$ J. A. Muñoz Rojas, loc. cit., pág. 119. 
Trinidad de Rojas (1830-1902) fue un hermano de su abuelo, descrito por López Estrada en su prólogo de Antequera, norte de mi pluma como «uno de los más activos representantes del grupo romántico antequerano, tanto en lo que toca a la creación en prosa y verso como en lo que representó para el conocimiento de la tradición literaria de la ciudad» $»^{25}$.

Lo más significativo es enterarse de lo que supone para Muñoz Rojas esta relación familiar con el poeta romántico, pues el niño tenía noticia de D. Trinidad, de su gran biblioteca y de cómo estaba. En La gran musaraña, precisamente el capítulo «La canción del pirata» — título del poema de Espronceda, muerto cuando D. Trinidad tenía doce años- el antequerano evoca la figura de su tío ${ }^{26}$. Para probar la huella que ha dejado sobre nuestro poeta es preciso acudir a Historias de familia, precisamente la parte de «Historias fantásticas y de poetas» donde Muñoz Rojas, al referirse a los personajes de la Leyenda de los enamorados, cita a su tío porque - como también comenta Rodríguez Marín - Trinidad tenía un poema en latín de dicha leyenda acompañado por una traducción al castellano:

Don Trinidad de Rojas, lúcido ingenio antequerano, a juzgar por las muestras que de su pluma conozco, poseía o posee un poema latino que trata del propio asunto y que está acompañado de su traducción en verso castellano ${ }^{27}$.

Claro que esta leyenda, una trágica historia del amor entre el cristiano y la morisca, forma parte del acervo tradicional de Antequera e interesó a algunos escritores románticos como Washington Irving, el autor de Cuentos de la Alhambra, cuya obra conocía nuestro poeta ${ }^{28}$, pero pensamos directamente en su tío Trinidad para justificar el interés de Muñoz Rojas por esta leyenda. Esto no quiere decir que José Antonio, al reproducir la leyenda en la «Leyenda de la peña», lo hiciera al mismo modo del poema hallado por don Trinidad o con los detalles de la leyenda tal como están en los libros anteriores. Pues, el antequerano afirma:

25 J. A. Muñoz Rojas, Antequera, norte de mi pluma, pág. 11.

${ }^{26}$ A este respecto nuestro poeta relata: «En la familia hubo un poeta, tío Trinidad, vaya nombre, llamarse Trinidad, hermano de mi abuelo, malísimo para los negocios, tenía una gran biblioteca, aquí vivió, ser poeta, se podía ser muchas cosas, cierto que las que entonces nos tentaban eran otras, ser marino o carpintero [...]. Los versos tampoco eran cosa de provecho, con lo bien que sonaban y el gusto que daba oírlos y decirlos. Ya ves, tío Trinidad murió arruinado» (J. A. Muñoz Rojas, La gran musaraña, Pretextos, Valencia, 1994, págs. 71-72).

${ }^{27}$ F. Rodríguez Marín, Luis Barahona de Soto, estudio biográfico y bibliográfico y crítico, Real Academia Española- Sucesores de Rivadeneira, pág. 190. <http://www.cervantesvirtual. com/obra/luis-barahona-de-soto-estudio-biografico-bibliografico-y-critico $>$ [consulta: 14 de diciembre de 2014].

${ }_{28}$ Muñoz Rojas prologó el libro Antequera de Washington Irving, de Antonio Parejo Barranco (Excmo. Ayuntamiento de Antequera, 2003). 
Cada uno la cuenta a su modo [...]. Por eso yo no he hecho mucho caso de un Southey o de un Vilches, ni incluso de mi mismo tío Trinidad, que la escribió en un precioso verso romántico, en el que la aprendió toda la familia ${ }^{29}$.

Trinidad de Rojas no fue el único poeta perteneciente a la familia de Muñoz Rojas. Tío Ramiro es otro de los evocados en Historias de familia y Sonetos de amor por un autor indiferente. Y, dejando aparte lo real y fantástico en este personaje ${ }^{30}$, resaltamos aquí el comentario de Juan de Dios Ruiz-Copete

${ }^{29}$ J. A. Muñoz Rojas, Historias de familia, Pretextos, Valencia, 2000, pág. 105.

${ }^{30}$ A pesar de los aspectos fantásticos en los relatos relacionados con este personaje, es significativo acercarse e indagar sobre el contexto en que fue creado por Muñoz Rojas para aprobar el apego de nuestro poeta a la tradición de su tierra y de su familia. En el prólogo de Sonetos de amor por un autor indiferente, el poeta colige la atribución de estos versos a su tío Ramiro, un personaje tan curioso: «¿Entonces? Yo siempre sospeché que tío Ramiro, alguna de cuyas dichas y desdichas tuve ocasión de referir en otro lugar, hubiera dejado tras sí algo más que epístolas y primores genealógicos, y siempre mantuve viva la esperanza de encontrarme de manos a boca, en el rincón menos esperado, con el fruto de su corazón» (Muñoz Rojas, Obra completa en verso, pág. 120). En Historias de familia, nuestro antequerano trata este personaje, pero no podemos confiar mucho en la autenticidad histórica de algunos detalles, datos ni narraciones, pues no se refieren a historias reales, como señala José Luis Cano a este respecto: «Estas Historias de familia tienen poco de ver con los cuadros de costumbres, literatura de vieja y castiza tradición de España. En los cuadros que pinta Muñoz Rojas - en los que el paisaje casi siempre está en función de enamorado o confidente del amor- no hay apenas costumbres ni bailes que retratar, porque los personajes evocados [...] son singularísimos y demasiado románticos para que puedan servir de guía a los historiadores de una época» (J. L. Cano, «José Antonio Muñoz Rojas y la poesía de su prosa», en Poesía española del siglo XX: De Unamuno a Blas de Otero, Guadarrama, Madrid, 1960, pág. 419). De todas maneras, hay una base realista sobre la cual Muñoz Rojas funda sus narraciones o crónicas sobre tío Ramiro y por eso no podemos hacer caso omiso de estos datos sin extraer algunas observaciones. De hecho, Cristóbal Cuevas afirma que nuestro poeta le comentó una vez que tras los nombres de tío Ramiro y Beatriz de Vibraye hay un fondo de realidad [C. Cuevas, «Ensayo introductorio», en J. A. Muñoz Rojas, Poesía (1929-1980), Málaga, Colección Ciudad del Paraíso, pág. 40]. Dado que el nombre de este personaje está mencionado sin apellido ni fecha concreta de nacimiento o muerte, aunque hace alusiones a otras fechas y caracterizaciones en el prólogo de Sonetos, suponemos que nuestro poeta no tenía documentos suficientes acerca de este poeta del siglo XIX. El nombre, entendemos, está inventado a base de otro personaje que es Ramiro, de la Leyenda de los Enamorados o inspirado en el héroe citado en los versos siguientes del antequerano Agustín Tejada Páez, otro familiar del poeta (A. Tejada Paéz, Poesías completas, edición de J. Morata, Grupo de Estudios Literarios del siglo de Oro, 2013, pág. 161. $<$ http://www.antequerano-granadinos.com/archivos/orden_tematico_pleno.pdf $>$ [consulta: 27 de diciembre de 2014]: «y, entre albornoces y almalafas rotas, / Ramiro y sus ejércitos triunfantes/altares le hacían/que con pías ofrendas componían/preñada espiga a quien el sol madura/el labrador le ofrece; /y, de cuanto la tierra se guarnece,/adorna el voto la ara con fe pura, / humeando en grato censo, / entre ocasiones mil, árabe incienso». Ahora bien, en primer lugar, según Muñoz Rojas, tío Ramiro desciende de una familia noble: «Tras la piel de las manos anda una sangre nacida en los doce nobles linajes de Soria que, sin embargo, no consigue ahuyentar la palidez de las mejillas» (J. A. Muñoz Rojas, Historias de familia, pág. 36). Damos por verídico este dato porque, como señala el propio José Antonio, en el siglo XIX el pueblo estaba formado por la vieja nobleza provinciana y la nueva burguesía campesina 
cuando ofrece que estas evocaciones de los personajes prueban la persistencia del pasado en el alma de nuestro antequerano:

Realidades de su vida idealizadas por la memoria y por la fantasía, más que personajes, que los hay - tío Ramiro, tío Ventura, la Villena, Riturqué y muchos más - lo que hay en estas estampas es un pasado que se instaló en su sensibilidad, constituyéndose en su pequeño universo íntimo y entrañable ${ }^{31}$.

Seguimos con el linaje de José Antonio Muñoz Rojas, que es descendiente lejano del poeta malagueño Juan de Ovando y Santarén ${ }^{32}$, gran amante de la

(cf. J. A. Muñoz Rojas, Ensayos anglo-andaluces, Pretextos, Valencia, 1996, pág. 201). En segundo lugar, cotejando la fecha en que se escribieron los Sonetos de amor (1856), siguiendo el fingimiento de nuestro poeta, con la época en que vivía tío Ramiro, y precisamente cuando tenía veinte años, en Historias de familia (la guerra carlista), juzgamos como reales las fechas mencionadas. En sus palabras preliminares a Sonetos de amor afirma: «En cuanto a la fecha de composición, los hay evidentemente compuestos a su lado [Beatriz de Vibraye], con toda probabilidad en el castillo de Sauvigny-le-Bois, en 1856, y otros en su ausencia pocos años después». Y en «Ya en el siglo XIX» de Historias de familia, dice sobre Ramiro: «Él es un oficial de la reina y mil veces ha ofrecido su pecho a las balas de los carlistas, sin que nunca lo hayan aceptado» (pág. 36). En tercer lugar, Ramiro está descrito como hombre de letras e historiador: «Usa su letra de primor para contarnos y dibujarnos una historia de historias de guerras de moros, caballeros que prestaban el propio caballo al rey cuando el rey había perdido el suyo, caballeros que yacían moribundos al pie de las Alpujarras altas. Guerras de moros y amores». Este rasgo lo ha mencionado Muñoz Rojas en sus palabras preliminares a los Sonetos (J. A. Muñoz Rojas, Obra completa en verso, págs. 119-120). En cuarto lugar, tanto en Historias de familias como en la nota preliminar de 1942, Muñoz Rojas nos transmite la descripción de Beatriz de Vibraye, Condesa de Suzenet, y amante de tío Ramiro. Las descripciones son idénticas, y esto puede dar autenticidad a algunos detalles, pues, Beatriz regaló a tío Ramiro un álbum lleno de hazañas de sus ascendientes, los Barnuevos, donde se pinta a sí misma: «[...] la mirada perdida y dulce, la frente alta y grande, los labios finos, el pelo caudalosamente partido en mitad de la cabeza, y aquellos trajes blancos que a tío Ramiro enamoraban» (pág. 119). En Historias de familia dice sobre ella: «En Dijon se pinta Beatriz de Vibraye a sí misma, una francesa por los cuarenta, con el pelo partido en dos a la mitad de la cabeza, recogido en crenchas a la altura de las orejas. El traje es de un color desvaídamente blanco y los ojos no tienen color. Son unos ojos que huyen y arrastran» (J. A. Muñoz Rojas, Historias de familia, pág. 37).

31 J. de D. Ruiz-Copete, Narradores andaluces de posguerra: historia de una década (1939-1949), Universidad de Sevilla, 2001, pág. 163. Muñoz Rojas sigue su indagación sobre el autor de estos Sonetos volviendo al pasado y agarrado a él: «Tampoco cabe la de D. J. [Se refiere a don Juan de Rojas], hermano del anterior y, como él, cantor legendario y su compañero en las lides del tiempo, porque sus obras nos son conocidas merced a los repetidos y fehacientes testimonios que él mismo se encargó de transmitirnos» (J. A. Muñoz Rojas, Obra completa en verso, pág. 119).

${ }^{32}$ He aquí algunos datos biográficos sobre Juan de Ovando y Santarén: «Nació en Málaga el 18 de enero de 1624, cuando a Góngora le quedaban sólo tres años de vida, y Quevedo tenía ya cuarenta y cuatro. Miembro de una familia distinguida, estudió latín y humanidades - parece que en Granada-, y luchó en Nápoles contra la rebelión que un tiempo encabezó Masaniello (1647-1648), perfeccionando su latín y aprendiendo italiano. Fue caballero de Calatrava y Capitán de las Milicias de Málaga. Casó dos veces de damas de alcurnia: primero 
literatura clásica. Nuestro poeta conoció la obra de su familiar, representada en diversos memoriales de súplica dirigidos al monarca de turno, y unas cuantas composiciones laudatorias para libros ajenos. Además, mostró un interés por su obra al publicar junto a Alfonso Canales (1950) ${ }^{33}$ un fragmento del Festín de las Musas y Noches de Apolo de dicho poeta áureo. Asimismo, conservaba los autógrafos de Ovando, conocidos como «Legajo Muñoz Rojas», estudiados después por Cristóbal Cuevas y Salvador Montesa:

Dicho manuscrito, al morir Ovando, hubo de pasar a poder de la segunda hija de su primer matrimonio, Ángela de Ovando y Rizo, casada con «el señor don Fernando Solana Parejo, vecino de la ciudad de Antequera». De él los heredó, a su vez, mediata o inmediatamente, don Manuel de Solano ${ }^{34}$, autor de una Historia de Antequera que se conserva en dicha ciudad, sin nombre de autor y manuscrita. Nada sabemos de su suerte posterior, salvo que su actual propietario lo prestó a José María de Cossío, lo que hizo posible su conservación, ya que en ese tiempo el Archivo y Biblioteca del autor de Las cosas del campo fueron pasto de las llamas ${ }^{35}$.

con doña Agustina Rizo, sobrina-nieta del consejero de María Estuardo, David Rizzi; luego con doña Rosa María de Negro, emparentada con una influyente familia genovesa. Leyó abundante literatura clásica - Homero, Platón, Virgilio y Lucano-, italiana -Petrarca, Ariosto, los Tasso [...] - y española — el romancero, la épica culta, historiadores de España e Indias, novelistas, dramaturgos y poetas como Cervantes, Lope, Quevedo, Calderón, y, sobre todo, Góngora-. Alcanzó íntegros los reinados de Felipe IV y Carlos II, y los primeros años de Felipe V, muriendo en 1706» [J. de la Victoria Ovando y Santarén, Autógrafos: (Manuscrito Muñoz Rojas), C. Cuevas y S. Montesa (transcripción, texto y estudio introductorio), Centro de Ediciones de la Diputación de Málaga, 1997, pág. 15].

${ }_{33}$ Alfonso Canales recuerda el tiempo en que preparaba la selección de poesía de Ovando con Muñoz Rojas rememorando algunas de las lecciones aprendidas por su maestro: «Vamos a hacer una colección de libros de poesía. Empezaremos por editar algo de este manuscrito de Ovando. ¿No crees que estos versos se refieren al Retiro? ¿Y yo qué sabía? ¿Y yo qué sé? Lo poco que sé me lo ha enseñado él: que no hay que desmedirse nunca; que no hay que despegarse nunca demasiado de la tierra; que hay sombras, inmediatas sombras que luchan por revivir en nosotros; que si no nos entregamos de vez en cuando al encanto de las musarañas, estamos perdidos» [A. Canales, «El maestro», El Mundo de Málaga (Papeles de la Ciudad del Paraíso), 30 de abril, 2009. Reeditado con el título, «El poeta antequerano visto por Alfonso Canales», El Mundo (cultura], 29/09/2009. <http://www.elmundo.es/elmundo/2009/09/29/andalucia_malaga/1254213486.html.> [consulta: 25 de febrero de 2014].

${ }^{34}$ Cristóbal Cuevas comenta en 1989 que Manuel Solano es «el historiador dieciochesco, que nos ha transmitido sus autógrafos poéticos» («Ensayo introductorio», págs. 14-15). El Diccionario bibliográfico-histórico de los antiguos reinos, provincias, ciudades, villas, iglesias y Santuarios de España de Tomás Muñoz y Romero (Atlas, Madrid, 1973, pág. 20) se refiere a este escritor perteneciente a la familia de Muñoz Rojas. Es autor de un libro sobre la historia de Antequera, donde penetra en muchos aspectos de la vida de esta ciudad; se trata de una compilación enriquecida por antiguos documentos de manera que sirve como testimonio de la historia de Antequera. Creemos que también en el caso de Muñoz Rojas se advierte una inclinación erudita como en el escritor dieciochesco.

${ }^{35}$ J. de la Victoria Ovando y Santarén, op. cit., pág. 16. 
José Antonio Muñoz Rojas mostró un especial interés por la figura de la Condesa de Luque, D. Micaela Díez de Tejada (1780-1857), la familiar de nuestro poeta «que tanto interesó a Rodríguez Moñino»" ${ }^{36}$. Una de las manifestaciones de esa atención se demuestra en el «Extraordinario carteo entre D. Antonio Rodríguez-Moñino y el autor, a propósito de la Dama Duende», donde Muñoz Rojas se refiere a un hallazgo: «Tengo en una carpetilla docena y media de cartas cruzadas entre El Galán Fantasma y la Dama Duende ${ }^{37}$, que no son otros sino Gallardo y la Condesa de Luque» ${ }^{38}$. Cierto es que nuestro poeta antequerano redactó esta carta fingida para elogiar el libro Epistolario que Antonio Rodríguez había escrito sobre su amigo don Bartolomé José Gallardo ${ }^{39}$.

Por su parte, Muñoz Rojas, arraigado en el pasado y relacionado con la herencia cultural de sus antepasados, finge haber recibido una carta de Rodríguez Moñino donde hace mención a su tía Doña Micaela Díez:

Madrid, 27 de noviembre 55

Sr. D. José A. Muñoz Rojas.

Velázquez, 92.

Amigo querido:

La Dama Duende se llamaba Doña Micaela Díez de Tejada y Díez de Tejada: nació en Antequera el 25 de noviembre de 1780, casó allí el 28 de diciembre de 1818 con D. Cristóbal Fernández de Córdoba Pérez de Barradas, VII Conde de Luque (n. Guadix, 27-II-1761; †Granada, 27-IV1833) y falleció en Madrid el 17 de septiembre de 1857, sin sucesión.

¿Averiguamos algo más?

Un cordial abrazo de

A. Rodríguez-Moñino

Pero, en realidad, Muñoz Rojas no fue el primero en tratar el tema de estas cartas mencionadas arriba; ya Félix de Llanos y Torriglia (1868-1949) en su Del rincón de mis autógrafos afirma que dentro del acervo epistolar que tiene salieron las cartas de Don Bartolomé José Gallardo ${ }^{40}$. En todo caso, nuestro

${ }^{36}$ C. Cuevas, «Ensayo introductorio», págs. 14-15.

${ }^{37}$ No se trata aquí de la Dama Duende, una obra clásica de Calderón de la Barca que el mencionado José Fernández Guerra comentó y publicó.

38 J. A. Muñoz Rojas, Antequera, norte de mi puma, pág. 65.

39 J. Miranda Valdés apunta: «El epistolario entre José Fernández-Guerra y Bartolomé José Gallardo lo ha estudiado el académico de la Española, Rodríguez Moñino, que curiosamente ocupó el sillón X, el mismo que ocupó Aureliano» [Aureliano Fernández Guerra (1816-1894), un romántico, escritor y anticuario, Real Academia de la Historia, Madrid, 2005, pág. 24].

${ }^{40}$ En una nota explica lo siguiente: «Por cierto que he rectificado posteriormente la hipótesis que entonces desarrollé utilizando los datos que nos proporcionara nuestro correspondiente granadino Díaz Martín (q. e. p. d). Casi seguramente, no fue don José Vicente Alonso el corresponsal erudito a quien iban dirigidas las cartas de Gallardo, aunque después de todo no lamento haber divulgado con tal ocasión datos biográficos poco conocidos de aquel estimable literato. Releyendo más tarde La batalla de Lucena y las notas de su autor, Don Agustín 
poeta penetró más en el espíritu de estas cartas, vivió con sus palabras, viajó por sus mundos. El poeta, al comentar en La gran musaraña que «Siempre ha sido mi vida rica en estos encuentros singulares con mujeres mayores, en lo que sin duda influía mi condición de huérfano temprano» ${ }^{41}$, se encuentra y establece un diálogo íntimo con su tía Micaela, reflejando su delicia ante este encuentro espiritual entre él y esta mujer. El poeta se queda asombrado ante este viaje por mundos lejanos y nuevos que pudo pisar gracias a las cartas encontradas:

$¡ \mathrm{Oh}$, doña Micaela, las fortunas nunca vienen solas! ¡No siempre se ha de decir de los descalabros! Mira por qué bendita casualidad, llegó poco después a mi alcance un armario de papeles antiguos ¡Oh delicia, delicia, qué diversos nombres tienes para los mortales! Cuando me veían ir furtivamente encerrarme con los papeles, presentía yo en las miradas de las gentes, no sé qué mezcla de extrañeza y compasión. Perderse lo que quedaba fuera, pensaba, sin duda. Con mis ojos interiores correspondía yo a aquellas miradas y pensaba: ipobres, perderse lo que esto guarda dentro! Nadie que no se haya enfrentado con estos tesoros diga esta boca es mía. ¡Qué Américas, qué pacíficos, qué alegría de nuevos países, qué adelantamientos de tierras nuevas, en tiempos nuevos, encerraban estos papeles! ${ }^{42}$

Se trata de un poeta acostumbrado a interpretar las cartas escritas con letras picudas, casi ilegibles ${ }^{43}$, ya que su afición por esta tradición familiar le ha facilitado la tarea ${ }^{44}$.

González Amezúa, me he persuadido de que el literato y escritor con quien se carteaba el Galán fantasma era don José Fernández Guerra, padre de don Aureliano y don Luis. Pero lo más curioso del caso es que, habiendo errado el camino en cuanto a este intermediario entre don Bartolomé José y su valedora, acerté, a mi juicio, en todo respecto de quien sería la Dama Duende. Esta, en ambas hipótesis, es siempre doña Micaela Díez de Tejada, tercera Condesa de Luque, de quien consta fehacientemente que Fernández Guerra era devoto admirador y amigo» (F. de Llanos y Torriglia, Del rincón de mis autógrafos, Biblioteca virtual Miguel de Cervantes, Alicante, 2001. Edición digital a través de Boletín de Real Academia de Historia, 100, 1932, págs. 163-164. <http://www.cervantesvirtual.com/obra/del-rincon-de-misautografos.> [consulta: 13 de marzo de 2015].

${ }^{41}$ J. A. Muñoz Rojas, La gran musaraña, pág. 112.

${ }^{42}$ J. A. Muñoz Rojas, Antequera, norte de mi pluma, pág. 67.

${ }^{43}$ Nuestro antequerano recuerda: «La carta era a Gallardo y me divirtió mucho y la leíamos y releíamos en casa y nos dijimos: ¡vaya y cómo se las gastaban las señoras de aquella época! Para que luego nos vengan con letras picudas y conventicos galos. A mí, además, la manía me venía de antiguo, porque tengo cartas de prioras letradas y abuelas de pocas letras que dan ciento y raya a las de madamas con lenguas y otros títulos» (loc. cit., pág. 66).

${ }^{44}$ No olvidamos algunos hechos importantes relacionados con la conservación de la tradición por parte de nuestro poeta como el Cancionero antequerano, que es el conjunto de tomos manuscritos coleccionados por don Ignacio de Toledo y Godoy en la ciudad de Antequera, por los años 1627-1628 y guardado por mucho tiempo en la biblioteca de la Caja de Ahorros de Antequera gracias a nuestro poeta. Se encuentra en la actualidad depositado en el Archivo Histórico de la ciudad. En una entrevista, Muñoz Rojas aclara que el Cancionero antequerano 


\section{EL GARCILASISMO Y SU RECEPCIÓN POR MUÑOZ ROJAS}

\subsection{El garcilasismo y el arraigo}

El año del estallido de la guerra civil, 1936, coincidió con el centenario de la muerte de Garcilaso, un hecho que dividió a los poetas e intelectuales españoles en partidarios de las tendencias vanguardistas y los que se adherían a la cultura clásica del Renacimiento. Según señala Fanny Rubio:

pertenecía a la familia de Pepe Bergamín: «Su madre era antequerana; el cancionero, cuando la guerra, lo tenía Dámaso Alonso, cuando Pepe volvió lo reclamó, después él se lo compró y ahora está en la biblioteca antequerana» («José Antonio Muñoz Rojas, Diálogo en La Casería: otras cosas, y el campo», Entrevista por D. Pérez Venegas, Quimera, 266, 2006, págs. 42-43). Por su parte, Juan Benítez Sánchez resalta el papel de nuestro antequerano en la publicación del Cancionero Antequerano por parte de Dámaso Alonso y Rafael Ferreres en Madrid el año 1950 («A José Antonio Muñoz Rojas», Estudios antequeranos, X, 1997, pág. 432). Dámaso Alonso dedica la edición a José Antonio escribiendo: «También durante algún tiempo, en fase más avanzada, ha participado en nuestra labor José Antonio Muñoz Rojas, y así nos enriquecemos con su mucha erudición de historia antequerana, y después nos ha enviado muchos datos: se puede decir que siempre que se citan noticias procedentes de protocolos antequeranos o actas del Cabildo municipal de Antequera, se las debemos a él» (D. Alonso y R. Ferreres, eds., Cancionero antequerano 1627-1628, Instituto Miguel de Cervantes, Madrid, 1950, pág. XV). La erudición de Muñoz Rojas en este contexto reside sobre todo en acercarse a la figura de don Ignacio de Toledo y Godoy, de quien apenas existían noticias, y gracias al cual puede seguirse el hilo de la poesía antequerana de su tiempo (J. A. Muñoz Rojas, Antequera, norte de mi pluma, pág. 53). En la misma línea, hacemos especial atención a la publicación de las cartas y documentos relacionados con la historia y tradición de Antequera, como es el caso, por ejemplo, de las «Cuatro cartas inéditas de Agustín de Tejada (1567-1653)». Muñoz Rojas afirma que la figura de Agustín Tejada Páez «es en sí misma singular, no sólo en cuanto poeta, sino como historiador y autor de poemas y leyendas sobre hazañas antequeranas, desgraciadamente en buena parte perdida» (J. A. Muñoz Rojas, "Cuatro cartas inéditas de Agustín de Tejada», Revista de Estudios antequeranos, 2, 1993, pág. 411). Por último, el impulso de la reconstitución de la Academia de las Nobles Artes de Antequera, fundada a finales del XVIII, es una de las manifestaciones de la conservación de la tradición de su ciudad y familia. Nuestro antequerano, rodeado por muchos intelectuales, la presidía hasta su muerte y en ella veía una prolongación de la famosa Cátedra de Gramática que distinguió a la ciudad y a su grupo poético en el Siglo de Oro (J. A. Muñoz Rojas, Ensayos angloandaluces, pág. 19): «Parece extraño hablar de la Gramática como caracterizadora de una escuela cuando hoy la Gramática sólo figura como una parte, a veces mínimo y no apreciada, de las muchas materias que se enseñan en cualquier centro. San Agustín llamó a la Gramática puerta de sabiduría, y que sin gramática no se podía entrar entonces en ningún recinto de la cultura (me atrevería a afirmar que ni incluso ahora), como su acceso natural que era. Pues bien, esa modestísima escuela, tan modesta que hubo de albergarse en unas tiendas que había en la entonces Plaza Mayor de la Villa, la hoy de Santa María, fue el origen de esa otra escuela poética antequerana de que se gloría la ciudad». Para más información sobre la escuela de Gramática véase J. Escalante Jiménez y M. Fernández Paradas, «Las Historias de Antequera: una aproximación a los orígenes de la historiografía antequerana (siglos XVI-XVII)», Baética: Estudios de arte, geografía e historia, 2003, 25, págs. 683-696. Ver también J. Lara Garrido, «La Cátedra de Gramática de la Iglesia Colegial y la cultura humanística. Elementos para un encuadre de la poesía antequerana en el Siglo de Oro», en La Real Colegiata de Antequera: Cinco siglos de arte e historia (1503-2003), Ayuntamiento de Antequera, 2004, págs. 221-258. 
Góngora, para los primeros, y Garcilaso, para los segundos, fueron banderas que tomaron en la marcha de los acontecimientos un significado por sí solas. Sus simples nombres evocaban para quien los usara una toma de posición, una actitud llevada a terrenos extraliterarios. Renacimiento y barroco sonarán a materias irreconciliables durante algunos años ${ }^{45}$.

Como reflejo de la actitud clásica adoptada por algunos poetas de la generación del 36 destacamos la aparición de la revista Garcilaso (1943-1946), que llevaba el lema en contraportada de su primer número 13 de mayo de 1943: «Siempre ha llevado y lleva Garcilaso», «Como el Greco contrastó a los hombres del 98, creemos y queremos que sea Garcilaso quien signe el pensamiento de los que podían encuadrarnos bajo las cifras decisivas de $1936 »^{46}$. En el primer número de esta revista leemos: «En el cuarto centenario de su muerte (1936) ha comenzado de nuevo la hegemonía de Garcilaso. Murió militarmente como ha comenzado nuestra presencia creadora. Y Toledo, su cuna, está ligada también a esta segunda reconquista, a este segundo renacimiento hispánico, a esta segunda primavera del endecasílabo». Esta vuelta a Garcilaso representa el anuncio de una actitud filosófica-poética que encarna el ideal del retorno a la tradición clásica.

En esta revista no cabe «hablarse de una única actitud »garcilasista», de una postura estética definida o exclusiva de determinado grupo» ${ }^{47}$, aunque A. G. de Lama señala en Cisneros algunos caracteres formales comunes entre los poetas colaboradores de Garcilaso: «[...] todos se inclinan a una métrica tradicional; miden los versos y los encajan en estrofas regulares. Hay octosílabos, endecasílabos, alejandrinos. Hay romances, liras y décimas. Y sonetos, muchos sonetos. Demasiados sonetos» ${ }^{48}$. Se trata, pues, de una voz tradicional respecto a la forma.

Destacamos ahora la relación entre el arraigo y la aparición de esta revista que es el punto de partida para los poetas del 36. Estos empezaron a colaborar en ella a partir del número 13 del año 1944. Es verdad que los poetas arraigados, en el sentido alonsiano, encontraron en Garcilaso la mejor expresión de su tendencia, como José Antonio Muñoz Rojas, un poeta que vivió su juventud en aquella etapa del florecimiento de las revistas, y Leopoldo Panero. Por eso hay quien relaciona el arraigo con esta revista al definir la poesía arraigada en estos términos:

Denominación que aplicó Dámaso Alonso a la poesía que en la posguerra cultivan un conjunto de escritores agrupados en torno a la revista Garcilaso, fundada en 1943 por José García Nieto. Son clasicistas en la forma, serenos en la expresión del sentimiento y aceptan sin protestas

\footnotetext{
${ }^{45}$ F. Rubio, Poesía española contemporánea, pág. 26.

46 J. García Nieto, Garcilaso: Juventud creadora, 1, 1943, pág. 1.

${ }^{47}$ F. Rubio, Las revistas poéticas españolas (1939-1975), Turner, Madrid, 1976, pág. 108.

${ }^{48}$ Loc. cit., pág. 114.
} 
las condiciones del mundo que les tocó vivir, muchas veces ayudados por sus convicciones religiosas, patentes en sus producciones ${ }^{49}$.

Esta definición relaciona el arraigo con esta revista, pues tal actitud estriba en la búsqueda del refugio, el asilo y el amparo a través de ciertos temas y formas. Por eso, Emilio Alarcos expone que el garcilasismo con sus metros y formas clásicas responde a la búsqueda del alivio en la melodía de los versos cantados. Y sobre los rasgos de la poesía inmediatamente posterior al conflicto bélico señala el profesor que se caracteriza por su tendencia formalista, con primacía de lo musical externo, el uso de melodías que pudieran dar sopor a los ojos fatigados por tres años de lucha ${ }^{50}$. Es el mismo sopor largamente voceado por los poetas arraigados que se alejan en sus poemas de los temas relacionados con la guerra y sus horrores.

La obra de Garcilaso de la Vega, como afirma Antonio Gallego Morell, tuvo una notable influencia a partir de 1548 y a lo largo de las diferentes etapas literarias, pero resaltamos aquí lo relacionado con la generación del 36 al que pertenece nuestro poeta:

[...] podríamos sorprender, ante todo, a Garcilaso como guía de una generación de escritores que militan en el campo poético del petrarquismo; corriendo los años, Garcilaso pasará a ser mentor lírico de otras generaciones que se van sucediendo hasta alcanzar el siglo XX en que, a partir del centenario de su muerte, se reavive este culto al poeta toledano [...] Abril, de Luis Rosales, y Égloga, de Alfonsa de la Torre, son libros poéticos a situar dentro de ese nacer garcilasista que desembocará en García Nieto cuando decide elegir el nombre del poeta para titular una revista de poesía que aspira a reagrupar a los poetas de la posguerra española ${ }^{51}$.

De esta forma, la recurrencia de algunos tópicos garcilasistas en la poesía de Muñoz Rojas es justificable sobre todo durante la etapa de los años cuarenta, cuando apareció la poesía arraigada y desarraigada en la poesía española. Por eso, siguiendo el criterio cronológico expuesto por Dámaso Alonso sobre la aparición de la poesía arraigada, nos fijamos en las dos obras Sonetos de amor y Abril del alma aparecidas en este período.

\subsection{Dos tópicos amorosos en Garcilaso de la Vega y Muñoz Rojas}

Empleamos en este análisis el concepto de «intertextualidad», centrándonos en el «intertexto» sin entrar en un «largo proceso genético en que interesaba ante todo un tránsito, un crecimiento, relegando a un segundo plano lo mismo

${ }_{49}$ A. M. Platas Tasende, Diccionario de términos literarios, Espasa, Madrid, 2002, páginas 646-647.

50 E. Alarcos Llorach, La poesía de Blas de Otero, Anaya, Salamanca, 1966, pág. 19.

51 Garcilaso de la Vega, Sonetos: Garcilaso de la Vega y sus comentaristas, ed. de A. Gallego Morell, v, Madrid, Gredos, 1972, págs. 11-12. 
el origen que el resultado ${ }^{52}$. Lo que intentamos poner de relieve es la existencia tópicos semejantes en Garcilaso de la Vega y José Antonio Muñoz Rojas.

La concepción amorosa de Garcilaso se inscribe en la tradición platónica, que rechaza el amor sensual frente al amor espiritual. La voz del poeta se oye en Sonetos de amor por un autor indiferente y en Abril del alma escritos en 1942 y 1943, respectivamente. Por eso, Concepción Argente del Castillo ve que la pertenencia de Muñoz Rojas a la generación garcilasista de posguerra está más o menos aceptada ${ }^{53}$. Asimismo, Enrique Baena señala que nuestro antequerano en estas dos obras canta el amor en términos humanísticos y en un tono que se aproxima al mundo de Garcilaso ${ }^{54}$.

Para comenzar, Fernando de Herrera, comentando la obra de Garcilaso, planteó el tema del amor platónico expresado por el poeta renacentista distinguiendo tres tipos de amor: el contemplativo o el divino, el activo o el humano y el bestial o terreno ${ }^{55}$. La visión platónica del amor basada en la de la Belleza, la Naturaleza se advierte claramente tanto la poesía de Garcilaso como en la de nuestro antequerano. Los tópicos que analizamos aquí delatan esta vía del amor:

\subsubsection{El poder de la mirada}

La vista es el primer paso al amor. En nuestro antequerano, como en Garcilaso, se trata de un proceso gradual que comienza con la apreciación de la belleza corporal de su amada, llegando a la belleza espiritual, la del alma y el carácter.

La mirada es importante en el acto amoroso, una fuente del deleite para el enamorado. En «Sonetos», de Abril del alma, se expresa el deseo de ver a la amada: «Sólo quiero los ojos para verte/y si los cierro es sólo por mirarte; / sólo vive mi alma de formarte, / mi corazón palpita con quererte» ${ }^{56}$.

Se trata de una mirada realizada por los ojos o por el corazón, es un acto continuo que no termina nunca: «siempre te estoy mirando y esperando, / que por algo los mares tienen olas $\rangle^{57}$.

Asimismo, en Garcilaso de la Vega, el amor entra por los ojos, por la vista, que es el más amado de todos los sentidos:

$$
\begin{aligned}
& \text { De aquella vista pura y ecelente } \\
& \text { salen espíritus vivos y encendidos, } \\
& \text { y siendo por mis ojos recibidos, } \\
& \text { me pasan hasta donde el mal se siente }
\end{aligned}
$$

$$
[\ldots]
$$

${ }^{52}$ C. Guillén, Entre lo uno y lo diverso, Crítica, Barcelona, 1985, pág. 313.

${ }^{53}$ C. Argente del Castillo, "Cantos a Rosa: una lección poética», Quimera: Revista de literatura, 266, 2006, pág. 20.

${ }_{54}$ E. Baena, Umbrales del imaginario: ensayos de estética literaria en la modernidad, Anthropos, Barcelona, 2011, pág. 32.

${ }^{55}$ Cf. Garcilaso de la Vega, Sonetos: Garcilaso de la Vega y sus comentaristas, pág. 329.

56 J. A. Muñoz Rojas, Obra completa en verso, pág. 150.

${ }_{57}$ J. A. Muñoz Rojas, loc. cit., pág. 149. 
Ausente, en la memoria la imagino; mis espíritus, pensando que la vían, se mueven y se encienden $\sin$ medida $^{58}$;

En los versos de ambos poetas la función del sentido de la vista (lo sensual) se compagina con la del corazón (lo espiritual); esto coincide con la exposición de Plutarco en la 5 Deca. de los Sermones convivales donde la mirada se considera como portadora del amor; a través de ella las imágenes del mundo exterior se transmiten al interior o espiritual ${ }^{59}$. Por eso Muñoz Rojas, al contemplar una fotografía de su esposa compone un poema pleno de metáforas del amor cortés, casi con la misma secuencia que los versos mencionados de Garcilaso ofrecen (imagen-contemplación-alma-recuerdo):

Esta adivinación de tu figura, esta impresión del alma que enternece el cristal, esta sombra que parece un recuerdo que sale en la espesura<smiles>[AlH2]</smiles>

comparación no admite con aquella imagen que yo llevo dibujada dentro del corazón en que te siento,

que donde va mi sangre va su huella, y donde van mis ojos su mirada, y donde va mi voz, pon su acento ${ }^{60}$.

Y como resultado de esta mirada, a veces aparecen algunas referencias eróticas o descripciones físicas de la amada tanto en los versos del antequerano como en los de Garcilaso ${ }^{61}$.

${ }^{58}$ Garcilaso de la Vega, Sonetos: Garcilaso de la Vega y sus comentaristas, pág. 111.

${ }^{59}$ B. Morros, «Las fuentes y su uso en las Anotaciones a Garcilaso», en Las «Anotaciones» de Fernando de Herrera, Universidad de Sevilla, 1997, pág. 45.

${ }^{60} \mathrm{~J}$. A. Muñoz Rojas, Obra completa en verso, pág. 126.

${ }^{61}$ Es verdad que el amor espiritual no impidiera a uno ni a otro contemplar la belleza corporal de la mujer. Por eso, Fernando de Herrera - al comentar estos versos del poeta de Toledo: «Con ansia estrema de mirar qué tiene, vuestro pecho encendido allá en su centro/y ver si a lo de fuera lo de dentro/en apariencia y ser igual conviene» (Garcilaso de la Vega, Sonetos: Garcilaso de la Vega y sus comentaristas, pág. 118) - señaló que el duro encuentro de la hermosura corporal impidió su intento de la consideración de la belleza del alma. Así que en el «Soneto XXIII», Garcilaso canta: «Y en tanto que el cabello, que en la vena/del oro se escogió, con vuelo presto,/por el hermoso cuello blanco, enhiesto,/el viento mueve, esparce y desordena» (pág. 118). Si el poeta renacentista exalta la figura de un cabello movido por el viento, Muñoz Rojas ve que todo el cuerpo está en vuelo: «muslos incesantes», «la libertad de tus senos» (Obra completa en verso, pág. 82). Los elementos sensuales palpitan de vez en cuando en sus versos. Cristóbal Cuevas, al hablar de Ardiente jinete — donde Muñoz Rojas denuncia la muerte del amor por desatención y reclama la necesidad de resucitarlo, inyectándole la ilusión del primer día-, señala que ello se logrará reconociendo «el valor de una sana 


\subsubsection{Locus amoenus}

Elevando con nuestros poetas a un grado más sublime el amor platónico que es el amor al mundo exterior como reflejo del amor de la mujer, observamos la aparición del tópico clásico locus amoenus o «lugar agradable» en sus versos. De hecho, la apreciación de la Belleza en sí, su esencia, hace que el amado se dirija al paisaje - un espacio natural idealizado en el caso de Garcilaso y muy realista en el caso de nuestro poeta - para contemplarlo y tratarlo como un testigo de su estado de amor. En Abril del alma leemos:

Mira el florido almendro donde asoma

con febrero la hoja primeriza,

y juntarse en la piedra de la herriza

lirio sin fruto a olivo sin aroma ${ }^{62}$.

El gozo y el placer por lo bello hacen al poeta repetir sus llamadas e invitaciones a la amada a disfrutar del paisaje, mirar el florido almendro, ofreciéndole un cuadro hermoso y armónico. En el caso del poeta renacentista se trata de un paisaje rico en elementos simbólicos relacionados con su estado de ánimo, como en Égloga I:

Corrientes aguas, puras, cristalinas, árboles que os estáis mirando en ellas, verde prado, de fresca sombra lleno, aves que aquí sembráis vuestras querellas, hiedra que por los árboles caminas, torciendo el paso por su verde seno: yo me vi tan ajeno del grave mal que siento, que de puro contento con vuestra soledad me recreaba, donde con dulce sueño reposaba, o con el pensamiento discurría

sensualidad, parte indispensable del banquete erótico» («Ensayo introductorio», pág. 101), como en los versos siguientes de ese poema: «No me hables con números o palabras, / sino con gestos o brincos / quiero ver y no oír, / quiero vivir y no recordar». El propio poeta antequerano explica que la «espalda» es una referencia erótica (Muñoz Rojas, Conversación 6.XII.88. Apud C. Cuevas, «Ensayo introductorio», pág. 101). Dice también: «La astronomía es imposible estudiarla de noche; /no tenemos más observatorio que tu espalda» (J. A. Muñoz Rojas, Obra completa en verso, pág. 72). Los versos siguientes de Canciones presentan el cuerpo de su amada como algo hermoso: «¿Adónde, dónde vais? ¡Si nos dijerais / adónde vuestra prisa va a llevaros, / en qué orillas se extienden las espaldas, /y cuáles aguas vuestros pies esperan!/Los ojos y las manos, los cabellos, / los hombros al igual que los collados, / los muslos incesantes, las colinas/que nombraremos senos, invenciones; / las cinturas, los brazos, las espaldas, / los ardientes cabellos como nubes, / las piernas cuyo oficio el aire adora, / los huesos con ternura, con dureza. /¡Oh belleza del cuerpo siempre en vuelo!» (pág. 81).

${ }^{62}$ J. A. Muñoz Rojas, Obra completa en verso, pág. 153. 
por donde no hallaba

sino memorias llenas de alegría ${ }^{63}$.

Aquí la Naturaleza es un testigo de los infortunios amorosos de dos pastores idealizados. Garcilaso, sufriendo los dolores causados por la muerte de Isabel de Freyre encuentra en el mundo exterior el consuelo y proyecta en él sus ansias.

Lo mismo se advierte en nuestro poeta en quien la Naturaleza y el paisaje cumplen una función curativa para el amante que confía en ellos y les remite sus quejas amorosas. Este común entroncamiento platónico se debe a que, empleando las palabras de C. Cuevas ${ }^{64}$, los dos poetas hicieron del amor una vocación ineludible, que llena la vida entera, justificándola en el simple ejercicio del amor. Ya nuestro antequerano anuncia en 1942 en Sonetos de amor « ¡Oh razón de mi vida y mi creencia!/Voz por quien canto y ojos por quien $\mathrm{veo} / \mathrm{en}$ medio de lo hondo y de lo oscuro» ${ }^{65}$, provocando una analogía con el Soneto V de Garcilaso: «Yo no nací sino para quereros» ${ }^{66}$. De esta forma, el hombre sintoniza con la naturaleza haciéndola singularmente capaz de entender su sentido. Así que en Abril del alma Muñoz Rojas canta: «levanta de su sueños de estupor a las cosas/y devuelve misión a la brisa y al río/y hace entenderse al mar con la amorosa playa» ${ }^{67}$.

Nuestro antequerano expresa el amor como una alegría que llamó a su puerta y después se dirige a la Naturaleza para conversar con ella en Abril del alma $a^{68}$ :

¡Oh primavera joven, con ternuras, con brisas todavía por febrero, que llegan a la sangre convocando delicias secretas que el invierno había lento sellado con su pie y aspereza, sacando frescos gozos de lo hondo de la entraña, estableciendo puentes entre júbilos varios, atando nuestra voz a la voz de las aves y nuestra sangre ansiosa de la sangre que sube y nuestros pies amantes de la tierra que pisan, lo mismo que el cabello del rapaz vientecillo o las hojas primeras de la luz del crepúsculo! 69

${ }^{63}$ Garcilaso de la Vega, Sonetos: Garcilaso de la Vega y sus comentaristas, pág. 166.

${ }^{64}$ C. Cuevas, «Ensayo introductorio», pág. 103.

65 J. A. Muñoz Rojas, Obra completa en verso, pág. 125.

${ }^{66}$ Garcilaso de la Vega, Sonetos: Garcilaso de la Vega y sus comentaristas, pág. 109.

${ }^{67}$ J. A. Muñoz Rojas, Obra completa en verso, pág. 138.

${ }^{68}$ Asimismo, su amigo de la generación, Luis Rosales — arraigado en su amor durante los años cuarenta y colaborador en Garcilaso - hace lo mismo en «Primavera del agua»: «iVen!, junto al sol que dorará las mieses/ está la luz donde nacimos juntos/y el lirio anunciador de la alegría» (L. Rosales, Obras completas, I, Madrid, Trotta, 1996, pág. 170). La amada es invitada a compartir con él la belleza y alegría de la Naturaleza.

${ }_{69}$ J. A. Muñoz Rojas, Obra completa en verso, pág. 135. 
Amor y Naturaleza apenas se separan en la poesía de Muñoz Rojas. Conociendo las circunstancias en que el autor escribió sus obras de tema amoroso, se entiende la relación entre la belleza de la naturaleza y tal sentimiento ${ }^{70}$. Por otra parte, el poeta renacentista en «soneto XI» dirige sus palabras a las ninfas del río y las invita a escucharlo y consolarlo en su sufrimiento por la muerte prematura de una de sus amadas:

Hermosas ninfas que, en el río metidas, contentas habitáis en las moradas de relucientes piedras fabricadas y en columnas de vidrio sostenidas;

\section{[...]}

dejad un rato la labor, alzando vuestras rubias cabezas a mirarme, y no os detendréis mucho según ando;

que o no podréis de lástima escucharme, o convertido en agua aquí llorando, podréis allá de espacio consolarme ${ }^{71}$.

Estamos aquí ante una Naturaleza humanizada capaz de comprender al amante y de apiadarse de su sufrimiento porque - también en palabras de Balbín - se encuentra sometida a la ley universal del amor: «las aves expresando sus penas a través del canto, la yedra ciñendo estrechamente el tronco de los árboles, que, a su vez, inclinan tristemente sus ramas..., y esto la convierte en el confidente ideal» ${ }^{72}$.

${ }^{70} \mathrm{El}$ antequerano relata que Cantos a Rosa se le ocurrieron de pronto, de golpe, en el campo (Á. García, «El poeta en el tiempo: entrevista a José Antonio Muñoz Rojas», El maquinista de la generación, 17, 2009, pág. 111).

${ }^{71}$ Garcilaso de la Vega, Sonetos: Garcilaso de la Vega y sus comentaristas, pág. 112.

${ }^{72}$ Garcilaso de la Vega, Garcilaso de la Vega y otros poetas cortesanos (ed. de R. Balbín), Castalia, Madrid, 2005, págs. 14-15. 
